\title{
A função política do luto por Marielle Franco
}

Carla Rodrigues, Universidade Federal do Rio de Janeiro

Tássia Áquila Vieira, Universidade Federal do Rio de Janeiro

O objetivo desse artigo é refletir sobre certas manifestações de luto pela execução da vereadora carioca Marielle Franco, de forma a articular os seus aspectos políticos com as proposições sobre distribuição desigual do luto público da filosofia de Judith Butler. Desenvolvemos como hipótese a ideia de que o luto por Marielle Franco promove uma mistura entre as formas oficiais de luto e as formas populares e espontâneas, nas quais há um duplo movimento de reconhecimento. Nessa duplicação está a possibilidade ético-política de reafirmar a importância da pergunta de Butler "quando a vida é passível de luto?”.

PALAVRAS-CHAVE: Luto. Reconhecimento. Marielle Franco. Judith Butler. 
A morte nos impõe suas próprias leis.

Antígona

E se somos Severinos iguais em tudo na vida, morremos de morte igual, mesma morte severina: que é a morte de que se morre de velhice antes dos trinta, de emboscada antes dos vinte, de fome um pouco por dia (de fraqueza e de doença é que a morte severina ataca em qualquer idade, e até gente não nascida).

Somos muitos Severinos iguais em tudo e na sina: a de abrandar estas pedras suando-se muito em cima, a de tentar despertar terra sempre mais extinta, a de querer arrancar algum roçado da cinza. João Cabral de Melo Neto

\section{Introdução}

Numa concepção bastante alargada, podemos dizer que esse artigo começou a ser elaborado na manhã de 15 março de 2018, dia do velório da vereadora Marielle Franco, realizado na Cinelândia, na escadaria da Câmara Municipal do Rio de Janeiro, onde estava seu corpo assassinado na véspera. Naquele momento, o choque da morte dela e de 
seu motorista, Anderson Gomes, era tamanho que a maioria das pessoas presentes só conseguia expressar revolta e tristeza pela perda de uma mulher cuja força e liderança representava uma lufada de renovação na política carioca. Durante todo o dia, até que o cortejo saísse para o cemitério, a praça lotada exerceu o direito de enlutar em público a morte de uma mulher negra, oriunda da favela da Maré, eleita pelo PSOL com 46 mil votos na terceira maior votação do pleito municipal carioca de 2016. Brutalmente executada com 13 tiros, Marielle era uma liderança em ascensão, trabalhando num dos temas mais sensíveis da política fluminense, os altos índices de letalidade da ação policial. ${ }^{1}$

Naquele dia, também tinha início o projeto de pesquisa "Judith Butler: do gênero à violência de estado", desdobramento de um trabalho que vinha sendo desenvolvido desde 2016 a respeito da função política do luto na filosofia de Butler. ${ }^{2}$ Nossa presença no velório de Marielle Franco tinha pelo menos duas abordagens: a primeira, expressão de solidariedade e indignação que tomou uma grande parcela da população carioca e logo se manifestaria pelas capitais de todo o país; a segunda, iniciar ali a ampliação da pesquisa para abranger as políticas de luto por Marielle Franco como um fenômeno a ser acompanhado no âmbito do projeto. Aos poucos, conforme fomos recolhendo material sobre as inúmeras demonstrações de luto pela morte de Marielle, pudemos encontrar exemplos que nos ajudam a confirmar a hipótese inicial, qual seja, a de que o trabalho de luto por Marielle Franco nos forneceria um paradigma para pensar a distribuição desigual de luto público, uma das questões centrais da pesquisa da qual este artigo faz parte.

Por isso, um dos nossos objetivos é refletir sobre como as diversas formas de homenagem a Marielle Franco se enquadram no debate proposto pela filósofa Judith Butler sobre vidas enlutáveis. Para percorrer a essa ideia, vamos começar retomando a relação entre luto e estado de exceção discutida pelo filósofo Giorgio Agamben para, em seguida, apresentar a função política do luto tal qual pensada por Butler. Discutiremos, por fim, como as diferentes formas de simbolização da

1 Em 2019, dados do ISP indicam que a Polícia Militar bateu recordes de letalidade. Só no Estado do Rio, foram registradas 1.546 mortes de janeiro a outubro. É o maior número desde o início da série histórica, em 1998.

2 Estamos nos referindo ao projeto de pesquisa aprovado na Faperj, edital E-03/2017, programa Jovem Cientista do Nosso Estado, 2017, implementado em março de 2018 com três anos de vigência, com o qual foi possível mobilizar recursos para o acompanhamento das manifestações públicas de luto por Marielle Franco. 
perda de Marielle Franco podem ser pensadas a partir do modo como Butler mobiliza o luto como categoria ético-política.

\section{Luto e estado de exceção}

Em um capítulo muito específico do livro Estado de Exceção, o filósofo Giorgio Agamben trata da questão do luto a partir de uma pergunta: "como o iustitium, um termo do direito público, que designava a suspensão do direito numa situação da maior necessidade política, pôde assumir o significado mais anódino de cerimônia fúnebre por ocasião de um luto?" (AGAMBEN, 2004, p. 102). O que nos interessa na questão de Agamben é a referência ao que ele considera uma "estranha passagem" que fez com que o termo iustitium - cujo significado literal era "suspensão do direito" - tenha passado, com o tempo, a designar luto público. Encontramos na identificação entre suspensão do direito e luto público a hipótese de propor uma relação entre direito ao luto e estado de exceção, nos apoiando em Agamben:

Os romanistas e os historiadores do direito não conseguiram ainda encontrar uma explicação satisfatória para a singular evolução semântica que leva o termo iustitium - designação técnica para o estado de exceção - a adquirir o significado de luto público pela morte do soberano ou de um parente próximo a ele. (...) Como os períodos de anomia e de crise, em que se assiste a um desmoronamento das estruturas sociais normais e a uma falência dos papéis e das funções que pode chegar a completa inversão dos costumes e dos comportamentos culturalmente condicionados, assim também os períodos de luto são, frequentemente, caracterizados por uma suspensão e uma alteração de todas as relações sociais (AGAMBEN, 2004, p. 101).

Em seguida, Agamben cita o romanista Willian Seston, observando que as explicações para a passagem de iustitium a luto público são "insuficientes":

Nos funerais imperiais, sobrevive a recordação de uma mobilização. Enquadrando os ritos fúnebres em uma espécie de mobilização geral, suspendendo os negócios civis e a vida política normal, a proclamação do iustitium tendia a transformar a morte de um homem numa catástrofe nacional, num drama em que cada um, querendo ou não, era envolvido (SESTON, 1962, p. 171 ss, citado por AGAMBEN, 2004, p. 104, grifos nossos.) 
Nossa percepção é que podemos enquadrar os rituais fúnebres por Marielle, cujo assassinato foi uma catástrofe nacional, num paradigma de suspensão da "vida política normal". Para isso, vamos recuperar a distinção elaborada por Seston. Segundo o autor, vigorava na Roma antiga dois tipos de luto público: o decretado, que era precedido de uma consulta ao senado romano e interrompia todas as atividades, mesmo as de guerra; e o luto público dedicado aos mortos da família do imperador Julio Cesar, em que um ato legislativo organizava as provas de tristeza pública reivindicada aos cidadãos. Tudo se passa como se a distinção entre o luto decretado após consulta pública e o luto dedicado ao imperador desaparecesse: "o que se viu [com o tempo] foi uma mistura das manifestações de luto e das medidas de manifestação de ordem jurídica e militar que são próprias ao iustitium" (SESTON, 1962, p. 177). Essa recuperação histórica feita por Agamben e a palavra "mistura" usada por Seston (mêlée, no original em francês) nos servirão para pensar como se deu essa "mistura" entre a dimensão da perda individual e a perda coletiva por Marielle Franco.

$\mathrm{Na}$ nossa hipótese, o velório público na Cinelândia e as manifestações espontâneas que se seguiram pelas principais capitais do país nos permitem retomar a ideia agambeniana de mistura entre o luto público decretado por qualquer um mediante consulta pública e o luto dedicado ao soberano. Por ser titular de um mandato de vereadora, Marielle Franco pode ser velada na Câmara Municipal e ter as honras fúnebres declaradas pelo poder público. Essas formas institucionais de luto, garantidas pela equipe de seu gabinete na Câmara Municipal e pelo PSOL - organizadores do velório nas dependências da casa legislativa - se misturaram às demonstrações espontâneas de luto, mobilizadas por pessoas comuns, principalmente por mulheres e especificamente por jovens negras. 3 O iustitium por Marielle Franco tanto foi dedicado pelos poderes oficiais quanto foi decretado pela população carioca que enlutava uma vereadora da cidade e que, portanto, podia encarnar a sua representação. Há aqui nesse aspecto de representação a possibilidade ainda de pensar que os rituais fúnebres por Marielle eram uma rememoração de todos as pessoas negras moradoras de favelas já mortos por violência e para os quais não é possível decretar luto.

3 Agradecemos à professora Miriam Hermeto (UFMG) a aguda percepção sobre essa hipótese de leitura. 
Uma das explicações para que o termo iustitium, que designava estado de exceção, tenha se tornado a expressão para luto público, estaria, segundo Agamben, em um ponto em comum entre os dois - a anomia ou ausência de lei que marca tanto a declaração de estado de exceção quanto o luto público declarado para a suspensão da ordem vigente e a homenagem ao soberano. Em ambos os períodos, há uma proposital suspensão e alteração das relações sociais e da lei (Agamben, 2004, p. 102). O que estamos destacando nas manifestações - tanto no Rio de Janeiro quanto nas principais capitais do país - é a possibilidade de chamá-las de declaração de estado de exceção nos inúmeros movimentos de enlutar Marielle Franco. No dia do velório na capital carioca, a caminhada que seguiu da Cinelândia para a Assembleia Legislativa, onde havia um ato de protesto organizado pelo PSOL, seguia em um silencioso e impressionante cortejo, conquistando ali, na ocupação daquele espaço, o direito ao luto. Era impossível que qualquer transeunte saindo do trabalho ou se movimentando pelo centro do Rio de Janeiro ficasse indiferente à multidão vestida de preto que caminhava em cortejo e evocava: "Marielle, presente. Hoje e sempre". Foram essas primeiras formas de luto público que nos suscitaram a articular o significado ético-político do luto por Marielle Franco com o que já perseguíamos na filosofia de Butler. 4

Caberia começar então a pensar sobre a distinção entre vidas que importam e que, quando perdidas, devem transformar a "morte numa catástrofe", como escreveu Seston, e as vidas descartáveis em nome das quais o luto ficará restrito ao âmbito familiar e individual. É essa a formulação do diagnóstico da Butler quando pergunta "quando a vida é passível de luto?”, apontando que há vidas que, quando perdidas, nos dão a dimensão de falta, e há vidas que não chegaram a alcançar o estatuto de vidas com valor e por isso não alcançam o direito de serem enlutadas como perda coletiva. Marielle Franco foi ao mesmo tempo enlutada como perda individual e coletiva, representando, em seu assassinato, outras tantas vidas de mulheres, negras, moradoras de favela, que têm sido assassinadas sem direito a luto público, mantendo a perda restrita ao ambiente familiar e matando também a possibilidade de reconhecimento da vida perdida.

4 Agradecemos ao professor Guilherme Massara (UFMG) o diálogo em relação ao deslocamento do luto como categoria psicanalítica para categoria ético-política na filosofia de Judith Butler. 


\section{Luto e reconhecimento}

Quando a pesquisa dos rituais fúnebres por Marielle Franco começou, já havia, em nossos trabalhos anteriores, o debate sobre o tema do direito ao luto na filosofia política de Butler. Podemos localizar o tema o na obra de Butler desde seus primeiros livros, mas é na leitura que ela faz de Antígona, a tragédia de Sófocles protagonizada por uma mulher que morre em nome de honrar o direito de honrar o irmão, que a questão vai se tornando mais explícita. 5 Passa a ser uma questão para Butler pensar o luto como uma categoria que marca a diferença entre uma vida que teve valor e outra que não teve. Por isso, ela toma a reivindicação do luto em Antígona não apenas como uma mulher enfrentando o poder do Estado - como já haviam feito outras feministas, mas como paradigma do luto como luta por reconhecimento interditado. Reconhecimento que, lembra Butler, no roteiro proposto por Hegel (2011), deveria ser recíproco: tanto Antígona reconhece o valor da vida do irmão ao lutar pelo seu direito ao túmulo, quanto ela receberia a reciprocidade do reconhecimento ao honra a vida do irmão. ${ }^{6}$ Seguindo o que seria para Hegel o papel da irmã na família, a personagem de Sófocles estaria buscando um duplo reconhecimento: da vida de Polinices e do seu lugar na pólis. Nesse roteiro, Antígona buscaria o reconhecimento que a constituiria sujeita. Para Hegel, lembra Butler, a dialética em que se dá a relação entre o senhor e o escravo e a relação entre o marido e a mulher não tem reciprocidade na relação entre o irmão e a irmã. Neste par, a irmã só será reconhecida quando puder vir a honrar a morte do irmão. É só na morte que o irmão fornece reconhecimento à irmã, é com ele que Hegel argumenta que a irmã tem um dever supremo (HEGEL, 2011). Seguindo ainda o argumento de

5 Em Gender Trouble, Butler (1990) aborda a dificuldade de enlutar as pessoas que, na década de 1980/90, morriam de HIV/Aids sem que se pudesse explicitar a causa de suas mortes. A questão é retomada no livro seguinte, Bodies that matter (Butler, 1993) e ampliada a partir de Antigona's claim (Butler, 2000). Depois do 11 de setembro, Butler interpela a política oficial de luto estabelecida pelo governo dos EUA e desenvolve o debate em Precarious life (Butler, 2004), Frames of war (Butler, 2009) e Notes toward a performative theory of assembly (Butler, 2015).

6 Consideramos esse trecho de Antígona um dos exemplos da busca dela por reconhecimento para si mesma por meio do gesto de enlutar o irmão: “(...) uma esperança eu tenho: meu pai há de gostar de ver-me, e tu também gostarás muito, minha mãe, e gostarás também, irmão querido, pois quando morreste lavei-te e te vesti com minhas próprias mãos e sobre tua sepultura espargi as santas libações. E agora, Polinices, somente por querer cuidar de teu cadáver, dão-me esta recompensa. (...) Obedeci a essas leis quando te honrei mais que a ninguém (SÓFOCLES, 2001, p. 240, linhas 1000 a 1020). 
Butler, Antígona estaria cumprindo esse roteiro quando reivindica as honras fúnebres para Polinices e diz: "Não foi como escravo que ele morreu, foi como irmão". Ao reivindicar seu direito de honrar também a morte de Polinices, Antígona estaria reivindicando seu próprio direito ao reconhecimento.

É assim que as honras fúnebres para Polinices ganham a função de uma dupla superação - a da sua morte natural, a fim de marcar o início da vida do espírito, e a superação da consciência natural de Antígona que, ao arriscar a própria vida, faria a passagem da consciência natural para a consciência de si. Se, como quer Hegel, a morte é central na luta por reconhecimento, se é a morte que dá sentido à vida, então passa a ser preciso, seguindo a leitura de Butler, universalizar o direito ao luto como política e superar a hierarquia estabelecida por Creonte: há quem morra como herói e terá sua vida reconhecida pelo Estado, há quem morra como proscrito e não terá direito ao luto público. Essa distinção enquadra certos modos de vida como inteligíveis e outros não. Se um dos elementos da dialética do senhor e do escravo é o desejo de reconhecimento capaz de colocar a vida biológica em risco em nome de alcançar a vida do espírito, interditar essa passagem ao escravo, aos inimigos do estado ou às mulheres, seria equivalente a afirmar que existem a priori determinadas vidas que terão condição de possibilidade de ser reconhecidas e outras não, formulando então a pergunta, que está no subtítulo de Quadros de guerra: "quando a vida é passível de luto?" Cada mulher e, mais, cada mulher negra moradora de favela ou periferia que está enlutando Marielle Franco está também reivindicando seu próprio direito ao reconhecimento, num movimento recíproco como o que Butler reivindica para Antígona.

Se é a condição de enlutável que enquadra as vidas que têm e as que não têm valor, então passa a ser preciso, para Butler, universalizar o direito ao luto como mecanismo político de afirmar o valor de toda vida. É nesse sentido que a reivindicação do direito ao luto se torna, desde a leitura que Butler faz de Antígona, não apenas uma tarefa pessoal e familiar, mas um empreendimento coletivo, um direito, uma exigência e uma política de Estado. Vida e morte adquirem valor a partir do momento em que se estabelece uma diferença ativa entre uma e outra, de modo que não há valor absoluto nessa relação que, para Butler, é dialética: a vida do espírito, esta que merecerá ser enlutada, confere reconhecimento à vida biológica, mas sem as condições para que haja vida biológica não é possível que certas pessoas alcancem a vida do 
espírito. Há um futuro anterior - uma vida terá sido vivida - que torna possível dizer que para que uma vida venha a ser vivida é pressuposto que haja vida enlutável se for perdida. "Apenas em condições nas quais a perda tem importância o valor da vida aparece efetivamente. Portanto, a possibilidade de ser enlutada é um pressuposto para toda vida que importa (BUTLER, 2015, p. 32).

Marielle fez tudo que estava a seu alcance para tornar-se uma vida que importa. Sua trajetória começou na juventude, depois de ver sua melhor amiga morrer assassinada num tiroteio no Complexo da Maré. Dali em diante, fez o percurso que deveria bastar para superar sua condição de vida matável: foi aluna do pré-vestibular comunitário na Maré, criado para enfrentar o bloqueio histórico do ingresso dos moradores da favela na universidade; obteve bolsa de estudos para cursar Ciências Sociais na PUC-Rio; defendeu uma dissertação de mestrado no programa de Administração Pública da UFF (FRANCO, 2014; 2018). O que a execução de Marielle pretendeu dizer às pessoas negras e moradoras de favela que não é possível ou aceitável que saiam da sua condição de vida matável.7 $\mathrm{O}$ que as manifestações de luto por Marielle Franco permanecem dizendo é o quanto é inaceitável que essa distinção seja sustentada por políticas de Estado ou mesmo por forças paraestatais.

\section{Rua Marielle Franco}

Rituais fúnebres são práticas para lembrar aos vivos de amanhã a existência dos mortos de ontem e de hoje. "Celebração e rememoração são tentativas concretas de transformar a morte pessoal no objeto de um lembrar permanente, constante, de modo a confrontar o inevitável da morte de cada um com a imagem utópica de uma imortalidade coletiva",

7 Aqui, seria possível evocar inúmeras manifestações de vítimas da violência policial que tentam comprovar que seus familiares mortos eram "pessoas de bem", que não mereciam ser executadas pela polícia. Um dos exemplos mais recentes é a declaração de Aílton Félix, avô da menina Ágatha Vitória Sales Félix, de 8 anos, morta pela PM no Complexo do Alemão em setembro de 2019: "Foi a filha de um trabalhador, tá? Ela fala inglês, tem aula de balé, era estudiosa. Ela não vivia na rua não. Agora vem um policial aí e atira em qualquer um que está na rua. Acertou minha neta. Perdi minha neta. Não era para perder ela, nem ninguém". Do nosso ponto de vista, o depoimento é exemplar de duas questões: o empenho da família Félix em tornar a menina uma vida vivível; uma violência estrutural que autoriza, ainda que de forma implícita, que existam vidas matáveis. <https://g1.globo.com/rj/rio-de-janeiro/ noticia/2019/o9/21/parentes-de-menina-baleada-no-alemao-criticam-a-conduta-da-pmavo-se-desespera-ao-receber-noticia-da-morte.ghtml> 
como nos diz Jeanne Marie Gagnebin (2014, p. 15). Os rituais fúnebres por Marielle se misturavam entre aqueles que a enlutaram para reconhecê-la - o que, por sua vez, também produzia reconhecimento em quem se empenhava por honrar sua memória - e os que faziam do luto público uma forma de manter viva as suas lutas. Na celebração ecumênica realizada na Praça da Cinelândia no sétimo dia de sua morte, havia uma perceptível diferença entre as falas de pessoas que conheciam Marielle e as que estavam ali para protestar contra a violência arbitrária da qual ela foi vítima. De um lado, as pessoas que tinha com Marielle uma relação pessoa, sobretudo as mulheres negras, faziam celebrações pela perda individual do que Marielle significava para cada uma; de outro lado, muitos convidados e convidadas prestavam homenagens ao que a sua perda representava para a vida coletiva. Nessa celebração, a praça da Cinelândia já tinha outro perfil de público diferente do dia do velório. Misturavam-se entre os presentes pessoas que saiam do trabalho, pessoas que não necessariamente tinham estado no velório, pessoas que estavam ali participando de um comício: havia palmas, música, conversa, barulho, algazarra. O silêncio fúnebre que havia ocupado a escadaria uma semana antes dava lugar a um acontecimento político realizado e mobilizado em nome do luto por Marielle, já carregado de elementos simbólicos para além da perda individual, indicando que a execução de Marielle nos levava, coletivamente, a um tipo inédito de insegurança sobre o futuro.

Os protestos contra o seu assassinato começam então a se misturar aos protestos contra as diferentes formas de violência que marcam o cotidiano das pessoas negras e moradoras de favela no Rio de Janeiro. Foi ali também que começou o episódio que estamos identificando como um paradigma dessa mistura: a troca da placa de rua ao lado da Câmara Municipal. Num gesto simbólico, a placa oficial que indicava "Praça Floriano" foi sobreposta por uma placa similar batizando o lugar de "Rua Marielle Franco". Sabemos que nomear ruas, prédios públicos e monumentos são uma política de estado, que não se dá sem trâmites legais que dependem do poder Executivo. No dia seguinte à morte de Marielle, instado a dar um depoimento, o prefeito da cidade do Rio de Janeiro, Marcelo Crivella, anunciou que daria o nome dela a uma escola municipal em Pedra de Guaratiba. Esta política de nomeação, embora oficial, parecia dissociada do tipo de homenagem que a população da cidade pretendia prestar, marcando a memória por Marielle Franco nos lugares em que a história dela havia sido escrita. A 
placa na praça indicava, nesse sentido, a perpetuação de seu trabalho como vereadora e como defensora dos direitos humanos.

A placa foi retirada da Cinelândia em outubro, logo depois do primeiro turno das eleições, provocando a manifestação "Distribuição de mil placas para Marielle", convocada pelo site Sensacionalista, que inicialmente anunciou a intenção de arrecadar recursos para confeccionar 100 placas. A adesão à campanha foi tão grande que foram impressas 1,7 mil placas para o ato de 14 de outubro. Outras iniciativas, com o apoio da gráfica contratada para a primeira impressão, permitiram - e ainda permitem no site www.ruamariellefranco.com.br que qualquer pessoa encomende placas a preço de custo. Desde o primeiro ato de protesto, uma rede de voluntários se organizou em torno da campanha de espalhar as placas Rua Marielle Franco, que indica o número 307, no bairro do Estácio, local onde ela foi executada, e onde se lê: "(1979-2018) Vereadora, defensora dos Direitos Humanos e das minorias, covardemente assassinada no dia 14 de março de 2018”.

\section{Rua Marielle Franco}

(1979-2018) Vereadora, defensora dos Direitos Humanos e das minorias, covardemente assassinada no dia 14 de março de 2018.

\section{$307 \quad 20260-080$ Estácio}

Fonte: www.ruamariellefranco.com.br

A multiplicação das placas fez da iniciativa uma forma de protesto não apenas contra a violência da qual ela e o motorista Anderson Gomes foram vítimas, mas tornou-se um ato eleitoral. O contexto fluminense contava com um candidato que concorria ao governo do Estado do Rio de Janeiro com um discurso de "abate", buscando se identificar com o candidato à presidência da República pelo PSL, mesmo partido dos dois parlamentares responsáveis pela retirada 
da placa da Cinelândia. Num comício no final da campanha para o governo do Estado, esses mesmos deputados quebraram uma placa com o nome de Marielle Franco, expondo ali o quanto as políticas de memória pela vereadora estavam incomodando as forças políticas contra as quais ela lutava. Assim, a disputa pelo direito ao luto por Marielle Franco invadiu o cenário eleitoral de 2018. A reivindicação de reconhecimento foi a tônica em candidaturas de mulheres negras, algumas muito diretamente ligadas à Marielle Franco, como sua chefe de gabinete, Monica Francisco, que concorreu e foi eleita deputada estadual pelo PSOL nas eleições de 2018. Dados do Congresso em Foco indicam que o Estado do Rio de Janeiro foi o que mais teve candidaturas de mulheres negras nas eleições de 2018: 237 se candidataram, seis foram eleitas, um aumento de 151\% em relação aos dados das eleições de 2014.

Há inúmeras outras iniciativas de rememoração da vida de Marielle Franco: lugares batizados com seu nome, no Brasil e no exterior - como o Jardim Marielle Franco em Paris, uma estação de metrô em Buenos Aires e uma rua em Lisboa - são indicação de políticas de memória que buscaram promover reconhecimento à perda de uma vida cujo valor estava além da sua própria vida, simbolizando os valores e princípios pelos quais ela lutara. Interessa observar que a nomeação de lugares públicos é também um indicador da hipótese de mistura com que estamos trabalhando nessa pesquisa. É uma política oficial de luto público batizar praças, ruas e outros locais públicos como forma de inscrever esses nomes na história.8 Ou seja, é uma forma de luto que se assemelha ao luto decretado pelo soberano. No entanto, no caso da nomeação de lugares de memória por Marielle Franco, podemos pensar em dois tipos de iniciativa que se misturam: as oficiais, que decretaram o uso de seu nome por todo o país e também no exterior, como nos exemplos citados; e as iniciativas populares que declararam a necessidade de escrever seu nome na história. Uma mapa interativo, no qual quem tiver uma placa pode cadastrá-la, é um documento que atesta a força dessa iniciativa espontânea e popular.

8 Destacamos como paradigma de política de memória o projeto Rua Viva, que desde 1994 já renomeou 163 ruas da cidade de Belo Horizonte com nomes de militantes contra a ditadura militar, que substituíram nomes de pessoas ligadas ao regime de tortura, violência e opressão. 


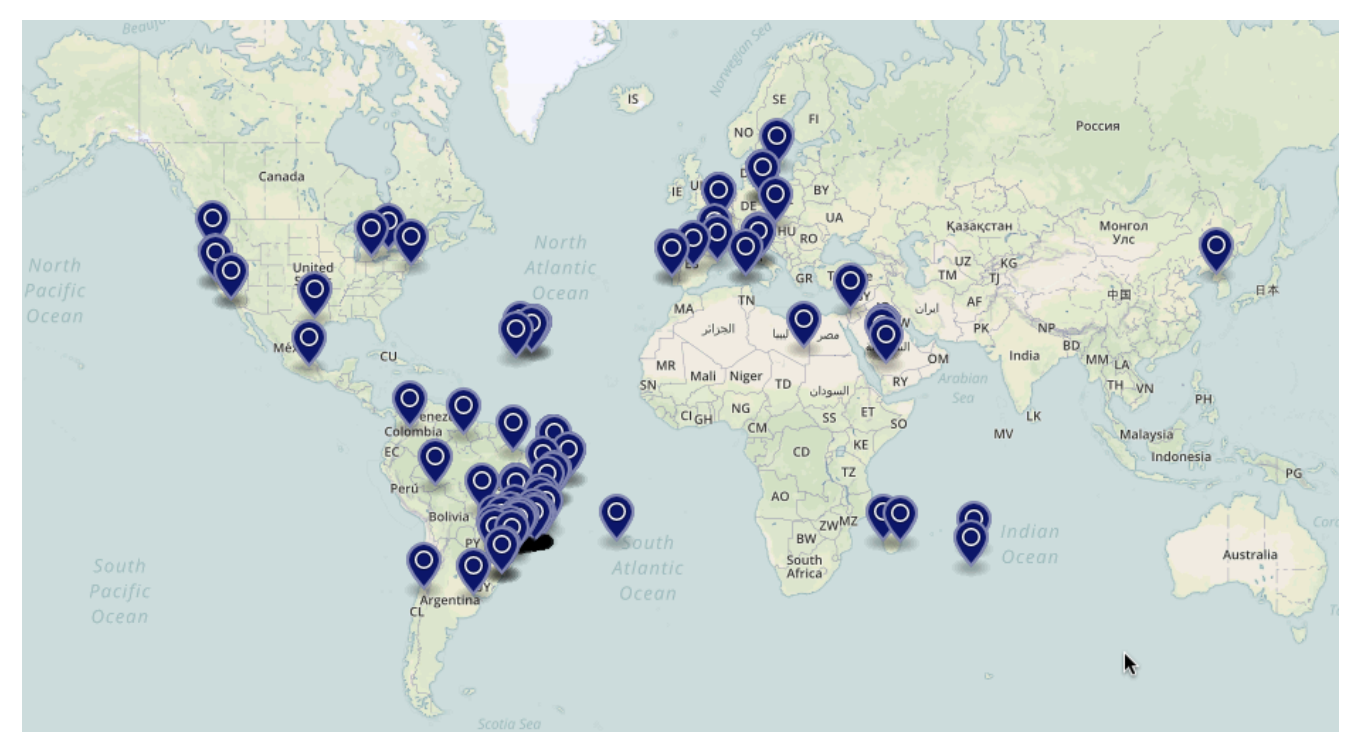

Fonte: www.ruamariellefranco.com.br

\section{Considerações Finais}

Seríamos, todos que seguem homenageando Marielle Franco e cobrando respostas pelo seu assassinato, capazes de saber exatamente o que perdemos com a morte dela? Ou podemos reconhecer a dimensão enigmática dessa perda? Para concluir, nos interessa observar que Butler retoma da teoria psicanalítica a dimensão de segredo que o luto contém: não somos capazes de saber o que perdemos no objeto perdido e a sua incorporação não se dá completamente.

Freud nos lembrou que quando perdemos alguém, nem sempre sabemos o que se perdeu daquela pessoa. Então, quando alguém perde, também se defronta com algo enigmático: há algo que se esconde na perda, algo que se perde nos recessos da perda. Se o luto envolve saber o que foi perdido (...), então o luto poderia ser sustentado por essa dimensão enigmática, pela experiência de não saber provocada pela perda que não podemos assimilar completamente (BUTLER, 2004, p. 21-22).

Buscamos argumentar neste artigo que o luto público por Marielle Franco funcionou e continua funcionando como um fundamento negativo para criar laços de identificação entre todos e todas aqueles que reconhecem e compartilham valores representados por Marielle Franco. Entendemos que a proposição de Butler é encontrar no luto esse fundamento negativo para a base de formação de novas comunidades não baseadas em identidade ou modos de exclusão. O 
trabalho coletivo de luto resgataria, assim, uma perspectiva de pertencimento que faz com que a vida seja compreendida como coletiva, o que Marielle Franco resumia tão bem com sua máxima de campanha: "Eu sou porque nós somos". Há o reconhecimento de inúmeras vidas que vieram antes de nós, não apenas na minha ancestralidade, mas também o reconhecimento ético-político de que todas as vidas estão sustentadas por redes de apoio e interdependência. Se acrescentamos a isso o caráter enigmático das perdas, talvez sejamos obrigada a reconhecer que não sabemos exatamente o que veio antes nem o que virá depois, o que nos colocaria na condição de despossessão que Butler quer mobilizar a fim de fazer da perda e do luto elementos centrais na sua crítica ao individualismo.

O tema da comunidade aparece precisamente na passagem em que Butler articula luto e política, propondo considerar que existe uma dimensão da vida política ligada à a nossa vulnerabilidade diante da perda e diante da tarefa de luto que se segue daí. É nesse ponto que ela procurar nessas condições de despossessão a base para uma comunidade (BUTLER, 2004, p. 19). É também essa dimensão do comum que recuperamos na próxima citação a Butler:

Muitas pessoas pensam que o luto é privado, que nos coloca em um situação solitária e, nesse sentido, despolitizada. Mas penso que o luto nos fornece um sentido de comunidade política de ordem complexa, e isso acontece, antes de mais nada, porque o luto traz à tona os laços relacionais que têm implicação na teorização da nossa dependência fundamental e da responsabilidade ética. (BUTLER, 2004, p. 22)

Estão expostos assim os argumentos que sustentam a nossa hipótese de que a função do luto na filosofia de Butler é o de constituir um laço social a partir da experiência de perda. Foi o que vamos tentar localizar nos rituais fúnebres e homenagens a Marielle Franco, mostrando como em torno do luto por Marielle tem se construído um laço de luta que reverbera e mantém vivo o seu legado pessoal, de quem superou a condição de vida matável mas nem assim - ou exatamente por isso - não conseguiu superar a condição de vida precária que marca a trajetória das mulheres negras nessa cidade, nesse estado, nesse país.

\section{Referências}

AGAMBEN, Giorgio. Estado de exceção. Tradução Iraci D. Poleti. São Paulo: Boitempo, 2004. 
BUTLER, Judith. Gender trouble: feminism and the subversion of identity. Nova York: Routledge, 1990. [Problemas de gênero feminismo e subversão da identidade. Tradução Renato Aguiar. Rio de Janeiro : Record, 2003.]

BUTLER, Judith. Bodies that matter. Routledge : Nova York, 1993. [ Corpos que importam. Tradução Verônica Daminelli e Daniel Yago Françoli. Revisão técnica Carla Rodrigues. São Paulo : N-1 Edições, 2019. ]

BUTLER, Judith. Precarious life. Londres e Nova York: Verso, 2004. [ Vida precária. Tradução Andreas Lieber. Revisão técnica Carla Rodrigues. Belo Horizonte : Autêntica, 2019.]

BUTLER, Judith. Antigone's claim. Columbia Un. Press : Nova York, 2000. [ O clamor de Antígona. Tradução André Checinel. Florianópolis: Editora da UFSC, 2014. ]

BUTLER, Judith. Frames of war - When life is grievable?. Verso : 2009. [ Quadros de guerra - quando a vida é passível de luto? Tradução Sérgio Lamarão e Arnaldo Cunha. Revisão técnica Carla Rodrigues.Rio de Janeiro : Record, 2015. ]

BUTLER, Judith. Notes toward a performative theory of assembly. Harvard Un. Press, 2015. [Corpos em aliança e a política das ruas notas para uma teoria performativa da assembleia. Tradução Fernanda Miguens. Revisão técnica Carla Rodrigues. Rio de Janeiro : Civilização Brasileira, 2018.]

FRANCO, Marielle. UPP - a redução da favela a três letras: uma análise da política de segurança pública do Estado do Rio de Janeiro. Dissertação de mestrado. UFF/Programa de Pós-graduação em Administração. Orientadora: Joana D’Arc Fernandes Ferraz, 2014.

FRANCO, Marielle. UPP. A redução da favela a três letras. São Paulo : N-1 Edições, 2018.

GAGNEBIN, Jeanne Marie. Limiar, aura e rememoração. Ensaios sobre Walter Benjamin. São Paulo: Editora 34, 2014.

HEGEL, F. Fenomenologia do espírito. Tradução Paulo Meneses. 6a Edição. Petrópolis, RJ: Vozes, 2011. 
RODRIGUES, Carla. A função do luto na filosofia política de Judith Butler. IN: CORREIA, A.; HADDOCK-LOBO, R.; SILVA, C. V. da. (orgs.). Deleuze, desconstrução e alteridade. Coleção XVII Encontro ANPOF: ANPOF, p. 329-339, 2017.

SESTON, William. Les chevaliers romains et le Iustitium de Germanicus. In: Scripta varia. Mélanges d'histoire romaine, de droit, d'épigraphie et d'histoire du christianisme. Rome : École Française de Rome, 1980. pp. $155-173$. h t t p s: / / w w w p e r s e e.fr/d o c / efr_0000-0000_1980_ant_43_1_1297].

SÓFOCLES. A trilogia tebana. Rio de Janeiro: Zahar, 2001.

VIEIRA, Tássia. Redesenhando o imaginário: processos de intervenções na Cidade de Deus no contexto de eventos esportivos. Dissertação de mestrado. Orientador Octavio Bonet. PPGSA/UFRJ, 2018. 


\section{The Marielle Franco grief as a political operation}

ABSTRACT: The claim in this article is to reflect on certain manifestations of mourning for the execution of councilwoman Marielle Franco, in order to articulate her political aspects with the propositions on the unequal distribution of public mourning of Judith Butler's philosophy. We developed as a hypothesis the idea that mourning for Marielle Franco promotes a mixture between official forms of mourning and popular and spontaneous forms, in which there is a double movement of recognition. In this duplication is the ethical-political possibility of reaffirming the importance of Butler's question "when life is grievable?". KEYWORDS: Grief. Recognition. Marielle Franco. Judith Butler.

Carla RODRIGUES

Professora de Filosofia (UFRJ), pesquisadora no Programa de PósGraduação em Filosofia (IFCS/UFRJ) e bolsista de produtividade da Faperj.

Tássia Áquila VIEIRA Antropóloga, mestre em Antropologia pelo PPGSA (UFRJ).

Recebido em: 28/12/2019

Aprovado em: 12/10/202O 